\title{
DETERMINAN KEJADIAN STUNTING PADA BALITA DI KOTA PADANG DENGAN MENGGUNAKAN ANALISIS REGRESI LOGISTIK ORDINAL
}

\author{
AINUN MARDIAH SIREGAR, IZZATI RAHMI HG, HAZMIRA YOZZA \\ Program Studi S1 Matematika, \\ Fakultas Matematika dan Ilmu Pengetahuan Alam, Universitas Andalas, \\ Kampus UNAND Limau Manis Padang, Indonesia. \\ email : ainunmardiahsir@gmail.com
}

Diterima 9 Maret 2019 Direvisi 7 April $2019 \quad$ Dipublikasikan 7 Mei 2019

\begin{abstract}
Abstrak. Status gizi pada balita merupakan salah satu indikator kesehatan yang perlu menjadi perhatian. Untuk mengetahui status gizi balita, dapat dilakukan dengan metode penilaian status gizi sehingga dapat ditentukan apakah seorang balita memiliki masalah gizi. Salah satu masalah gizi yang masih banyak terjadi pada balita adalah stunting (tubuh pendek). Menurut World Health Organization (WHO) suatu wilayah dikatakan memiliki masalah stunting jika persentase stunting berada di atas $20 \%$. Berdasarkan hasil Pengamatan Status Gizi (PSG) tahun 2016, salah satu daerah yang memiliki presentase stunting di atas $20 \%$ adalah Kota Padang. Oleh karena itu, pada penelitian ini akan dilakukan analisis yang bertujuan untuk menentukan faktor-faktor yang mempengaruhi kejadian stunting pada balita di Kota Padang dengan menggunakan analisis regresi logistik ordinal. Hasil analisis yang dilakukan menunjukkan bahwa faktor-faktor yang mempengaruhi kejadian stunting pada balita di Kota Padang adalah Pengetahuan orangtua, ASI Ekslusif, Diare, dan Pendapatan Orangtua.

Kata Kunci: Stunting, Regresi Logistik Ordinal, Balita
\end{abstract}

\section{Pendahuluan}

Keadaan gizi yang baik dan sehat pada masa balita adalah salah satu faktor utama kesehatannya di masa depan. Salah satu keadaan gizi yang tidak baik yang banyak terjadi pada balita adalah stunting(tubuh pendek). Keadaan ini dipresentasikan dengan nilai z-score tinggi badan menurut umur (TB/U) kurang dari -2 standar deviasi (SD) berdasarkan standar pertumbuhan menurut WHO [4].

Berdasarkan data Pemantauan Status Gizi (PSG) yang dilakukan oleh Kementrian Kesehatan RI pada tahun 2016 mencatat prevalensi stunting di Provinsi Sumatera Barat mencapai 25.5\%, dimana Kota Padang berada pada urutan ke-15 dari 19 Kabupaten/Kota di Sumatera Barat dengan angka prevalensi sebesar 21.1\% [3].

Menurut World Health Organization (WHO) suatu wilayah dikatakan memiliki masalah stunting jika persentase stunting berada di atas $20 \%$, sehingga dapat dilihat bahwa provinsi Sumatera Barat dan Kota Padang memiliki masalah gizi. Untuk mengantisipasi meningkatnya jumlah balita yang menderita stunting pada 
balita di Kota Padang maka perlu dilakukan penelitian lebih lanjut terhadap faktorfaktor yang mempengaruhi kejadian stunting pada balita di Kota Padang. Untuk itu perlu dibentuk model suatu hubungan antara tingkat kejadian stunting sebagai variabel respon dengan faktor-faktor yang diduga mempengaruhinya sebagai variabel prediktor.

\section{Tinjauan Pustaka}

Pada tinjauan pustaka akan dijelaskan mengenai penilaian status gizi dan metodemetode statistik yang digunakan pada penelitian ini.

\subsection{Statistika Deskriptif}

Statistika deskriptif merupakan metode statistik yang meringkas, menyajikan, dan mendeskripsikan data dalam bentuk yang mudah dibaca sehingga memberikan kemudahan dalam memberikan informasi (Walpole,1995). Analisis deskriptif dilakukan untuk semua variabel penelitian yang disajikan berupa tabel, diagram atau grafik, dan ringkasan data.

\subsection{Analisis Regresi Logistik Ordinal}

Metode statistika yang digunakan untuk menemukan hubungan antara variabel prediktor $(X)$ dengan variabel respon $(Y)$ dimana variabel respon mempunyai skala data ordinal dengan lebih dari dua kategori ialah regresi logistik ordinal. Model regresi logistik adalah sebagai berikut[1]:

$$
p_{i}=\frac{\exp \left(\alpha+\beta_{1} X_{i 1}+\beta_{2} X_{i 2}+\cdots+\beta_{k} X_{i k}\right)}{1+\exp \left(\alpha+\beta_{1} X_{i 1}+\beta_{2} X_{i 2}+\cdots+\beta_{k} X_{i k}\right)} .
$$

Peluang kumulatif didefinisikan sebagai berikut:

$$
P\left(Y \leq j \mid x_{i}\right)=\frac{\exp \left(\alpha_{j}+\sum_{t=1}^{k} \beta_{t} X_{i t}\right)}{1+\exp \left(\alpha_{j}+\sum_{t=1}^{k} \beta_{t} X_{i t}\right)}
$$

dengan $i=1,2, \cdots, n$ dan $j=1,2, \cdots, J$.

Secara sistematis model logit kumulatif dapat ditulis sebagai berikut.

$$
\operatorname{logit}\left(Y \leq j \mid x_{i}\right)=\ln \left(\frac{P\left(Y \leq j \mid x_{i}\right)}{P\left(Y>j \mid x_{i}\right)} .\right.
$$

Peluang kumulatif kategori variabel respon ke-j dapat dinyatakan sebagai berikut.

$$
P\left(Y \leq j \mid x_{i}\right)=p_{1}\left(x_{i}\right)+p_{2}\left(x_{i}\right)+\cdots+p_{j}\left(x_{i}\right)=\frac{\exp \left(\alpha_{j}+\Sigma_{t=1}^{k} \beta_{t} X_{i t}\right)}{1+\exp \left(\alpha_{j}+\Sigma_{t=1}^{k} \beta_{t} X_{i t}\right)} .
$$

Perbandingan antara peluang berhasil dengan peluang gagal antara dua individu disebut odds ratio. Untuk regresi logistik ordinal didapatkan nilai odds kejadian $Y \leq j$ terhadap referensi pada $x=x_{1}$ dan $x=x_{2}$ adalah sebagai berikut.

$$
O R=\left[\frac{P\left(Y \leq j \mid x_{1}\right) / P\left(Y>j \mid x_{1}\right)}{P\left(Y \leq j \mid x_{2}\right) / P\left(Y>j \mid x_{2}\right)}\right]=\exp \left(\beta^{\prime}\left(x_{1}-x_{2}\right)\right) .
$$


Parameter model regresi logistik ordinal dapat diestimasi menggunakan metode kemungkinan maksimum (maximum likelihood estimation) MLE. Metode kemungkinan maksimum pendugaan parameter regresi dilakukan dengan memaksimumkan suatu fungsi yang dinamakan sebagai fungsi kemungkinan yang dirujuk dari kepekatan peluang bersama dari variabel acak.

Berikut fungsi Likelihood untuk sample dengan n sampel random:

$$
L(\alpha, \beta)=\prod_{i=1}^{n}\left[p_{1}\left(x_{i}\right)^{y_{1 i}} p_{2}\left(x_{i}\right)^{y_{2 i}} \cdots p_{J}\left(x_{i}\right)^{y_{J i}}\right] .
$$

Dari persamaan di atas diperoleh fungsi ln-likelihood:

$$
\ln L(\alpha, \beta)=\sum_{i=1}^{n} \ln \left[y_{1 i}\left[p_{1}\left(x_{i}\right) y_{2 i} p_{2}\left(x_{i}\right) \cdots y_{J i} p_{J}\left(x_{i}\right)\right] .\right.
$$

Maksimum $\ln$-likelihood diperoleh dengan mendiferensialkan $\ln (L(\alpha, \beta))$ terhadap $\alpha$ dan $\beta$ dan menyamakan dengan nol. Turunan pertama dari $\ln (L(\alpha, \beta))$ terhadap $\alpha$ dan $\beta$ adalah fungsi nonlinear sehingga diperlukan metode iterasi untuk memperoleh estimasi parameternya. Untuk mendapatkan estimasi parameternya, maka dapat digunakan metode numerik, salah satunya metode Newton-Raphson. Formulasi iterasi Newton Raphson adalah sebagai berikut.

$$
\hat{\beta}^{(z+1)}=\hat{\beta}^{(z)}-\left(H^{(z)}\right)^{-1} g^{(z)},
$$

dengan banyak iterasi $z=1,2, \cdots$. Iterasi Newton-Raphson berhenti apabila

$$
\left|\hat{\beta}_{t}^{(z)}-\hat{\beta}_{t}^{(z-1)}\right|<\epsilon .
$$

Model yang telah diperoleh perlu diuji signifikannya, dengan melakukan pengujian statistik [2]. Pengujian yang dilakukan adalah:

(a) Uji G.

Uji ini bertujuan untuk mengetahui apakah terdapat pengaruh variabel prediktor yang digunakan secara bersama-sama terhadap variabel respon. Hipotesis:

$$
\begin{aligned}
& H_{0}: \beta_{1}=\beta_{2}=\cdots=\beta_{k}=0, \\
& H_{1}: \text { terdapat } \beta_{t} \neq 0 .
\end{aligned}
$$

Statistik uji yang digunakan adalah :

$$
G=-2 \ln \left[\frac{L(B)}{L(A)}\right]
$$

dimana

$$
\begin{aligned}
& L(A)=\text { fungsi likelihood model dengan seluruh variabel penjelas, } \\
& L(B)=\text { fungsi likelihood model tanpa variabel penjelas. }
\end{aligned}
$$

$H_{0}$ ditolak apabila $G>\chi_{(\alpha, v)}^{2}$ atau nilai $p$-value $<\alpha$.

(b) Uji Wald

Statistik uji Wald digunakan untuk menguji parameter $\beta_{t}$ secara parsial, dengan hipotesis sebagai berikut.

$$
\begin{aligned}
& H_{0}: H_{0}: \beta_{t}=0, \\
& H_{1}: \text { terdapat } \beta_{t} \neq 0,
\end{aligned}
$$


Pengujian ini dilakukan untuk setiap ${ }_{t}, t=1,2, \cdots, k$. Rumus umum statistik uji yang digunakan adalah:

$$
W_{t}=\left(\frac{\hat{\beta}_{t}}{S E\left(\hat{\beta}_{t}\right)}\right) .
$$

$H_{0}$ ditolak apabila $W>\chi_{(\alpha, 1)}^{2}$ atau nilai $p$-value $<\alpha$.

\section{Metode Penelitian}

Pada penelitian ini variabel respon $(Y)$ menggunakan indikator TB/U (tinggi badan terhadap umur). Berdasarkan keputusan Menteri Kesehatan Nomor 1995/MENKES/SK/XII/2010 mengenai kategori dari status gizi tinggi badan berdasarkan $z$-score yang diperoleh yaitu:

\begin{tabular}{|c|c|c|}
\hline Variabel & Kategori & Keterangan \\
\hline$Y_{1}$ & Sangat Pendek & $z$-score $<-3$ \\
\hline$Y_{2}$ & Pendek & $-3 \leq z$-score $<-2$ \\
\hline$Y_{3}$ & Normal & $-2 \leq z$-score $\leq+2$ \\
\hline$Y_{3}$ & Tinggi & $z$-score $>+2$ \\
\hline
\end{tabular}

Variabel prediktor $(X)$ yang digunakan pada penelitian ini adalah sebagai berikut:

Tabel 3.1 Variabel data Nominal

\begin{tabular}{|c|l|}
\hline Variabel & \multicolumn{1}{|c|}{ Keterangan } \\
\hline$X_{2}$ & Usia Balita \\
\hline$X_{3}$ & Berat Badan Lahir \\
\hline$X_{8}$ & Pengetahuan Ibu terhadap Gizi \\
\hline$X_{8}$ & Perilaku Ibu terhadap Gizi \\
\hline
\end{tabular}

Tabel 3.2 Variabel data Kategorik

\begin{tabular}{|c|c|c|}
\multicolumn{3}{|c|}{ Tabel 3.2 Variabel data Kategorik } \\
\hline Variabel & Notasi & Kategori \\
\hline Jenis Kelamin & D $_{11}$ & Laki-laki \\
\hline Pendidikan terakhir Ibu & $\mathrm{D}_{41}$ & SD \\
& $\mathrm{D}_{42}$ & SMP \\
& $\mathrm{D}_{43}$ & SMA \\
\hline Pendapatan Orang Tua & $\mathrm{D}_{51}$ & $<2$ juta \\
& $\mathrm{D}_{52}$ & 2juta-5juta \\
\hline ASI Ekslusif & $\mathrm{D}_{61}$ & ASI Ekslusif \\
\hline Diare & $\mathrm{D}_{71}$ & Diare \\
\hline
\end{tabular}

Langkah-langkah analisis data yang dilakukan dalam penelitian ini adalah sebagai berikut.

(1) Analisis deskripsi data.

(2) Analisis Regresi Logistik Ordinal:

a. Membentuk model dugaan regresi logistik ordinal dengan menggunakan seluruh variabel prediktor. 
b. Melakukan uji signifikasi seluruh model dugaan dengan regresi logistik ordinal dengan menggunakan uji G.

c. Memilih variabel prediktor yang signifikan berpengaruh terhadap variabel respon menggunakan uji Wald.

d. Menentukan model terbaik.

e. Mencari nilai odds ratio untuk masing-masing variabel prediktor yang signifikan berpengaruh.

f. Menginterpretasikan model regresi logistik ordinal.

g. Melakukan uji kesesuaian Model Regresi Logistik Ordinal dengan menggunakan uji Goodness of Fit.

\section{Analisis Dan Pembahasan}

\subsection{Deskripsi Data}

Data yang digunakan pada penelitian ini adalah data hasil survei Status Gizi Balita di empat kecamatan di Kota Padang yaitu kecamatan Kuranji, Nanggalo, Padang Barat dan Lubuk Kilangan yang berjumlah 281 data anak pada tahun 2017.

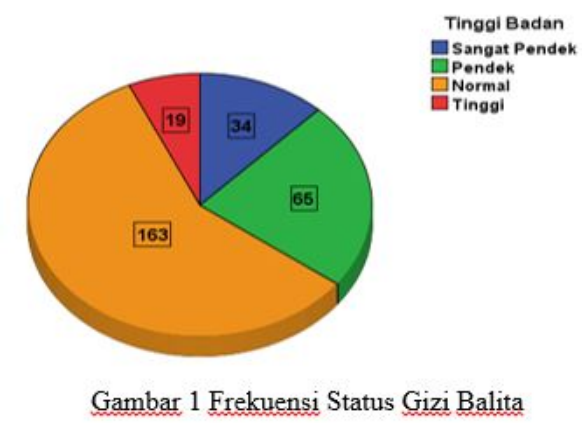

\subsection{Analisis Regresi Logistik Ordinal}

Tahap selanjutnya yaitu melakukan pemodelan regresi logistik ordinal. Banyaknya variabel prediktor yang digunakan adalah sebanyak 9 variabel dan variabel respon dengan 4 kategori yaitu sangat pendek, pendek, normal, dan tinggi. Tujuan dari pemodelan ini adalah untuk mengetahui faktor-faktor yang mempengaruhi kejadian stunting pada balita di Kota Padang.

Berdasarkan Tabel 4.1 dapat dilihat bahwa terdapat lima variabel yang diduga berpengaruh secara signifikan terhadap status gizi balita yaitu Berat badan lahir, Pengetahuan orang tua, ASI Ekslusif, Diare, dan Pendapatan orangtua $<2$ juta. Hal ini dilihat dari nilai p-value kurang dari $\alpha=10 \%$ atau nilai $\chi_{\text {hitung }}^{2}$ lebih besar dari $\chi_{(t a b e l)}^{2}$.

Lima variabel yang signifikan pada uji sebelumnya kemudian dilakukan estimasi parameter dan uji wald yang dapat dilihat pada Tabel 4.2. Berdasarkan tabel 4.2 dapat dilihat bahwa terdapat empat variabel yang diduga berpengaruh signifikan 
14 Ainun Mardiah Siregar dkk.

\begin{tabular}{|c|c|c|c|c|c|}
\hline Variabel & Parameter & Dugaan & Wald & $p$-value & Keputusan \\
\hline \multirow{3}{*}{ Konstanta } & $\alpha_{1}$ & 2.051 & 1.401 & 0.256 & \\
\hline & $\alpha_{2}$ & 3.569 & 6.408 & 0.027 & \\
\hline & $\alpha_{3}$ & 7.091 & 23.411 & 0.000 & \\
\hline $\mathrm{Usia}\left(X_{2}\right)$ & $\beta_{2}$ & -0.004 & 0.284 & 0.594 & terima $H_{0}$ \\
\hline $\begin{array}{l}\text { Berat Badan Lahir } \\
\left(X_{3}\right)\end{array}$ & $\beta_{3}$ & 0.525 & 4.190 & 0.041 & tolak $H_{0}$ \\
\hline $\begin{array}{l}\text { Pengetahuan Orang } \\
\text { Tua }\left(X_{8}\right)\end{array}$ & $\beta_{8}$ & 0.024 & 8.067 & 0.005 & tolak $H_{0}$ \\
\hline $\begin{array}{l}\text { Perilaku Orang Tua } \\
\left(X_{g}\right)\end{array}$ & $\beta_{9}$ & 0.013 & 1.234 & 0.267 & terima $H_{0}$ \\
\hline Laki-Laki $\left(D_{11}\right)$ & $\beta_{1}$ & -0.333 & 1.850 & 0.174 & terima $H_{0}$ \\
\hline ASI Ekslusif $\left(D_{61}\right)$ & $\beta_{6}$ & -0.690 & 3.850 & 0.050 & tolak $H_{0}$ \\
\hline Diare $\left(D_{71}\right)$ & $\beta_{7}$ & -0.807 & 8.153 & 0.004 & tolak $H_{0}$ \\
\hline \multicolumn{6}{|l|}{$\begin{array}{l}\text { Pendidikan Terakhir } \\
\left(X_{4}\right)\end{array}$} \\
\hline $\mathrm{SD}\left(D_{41}\right)$ & $\beta_{41}$ & -0.084 & 0.018 & 0.894 & terima $H_{0}$ \\
\hline $\operatorname{SMP}\left(D_{42}\right)$ & $\beta_{42}$ & -0.398 & 0.438 & 0.508 & terima $H_{0}$ \\
\hline $\operatorname{SMA}\left(D_{43}\right)$ & $\beta_{43}$ & 0.468 & 0.499 & 0.480 & terima $H_{0}$ \\
\hline \multicolumn{6}{|l|}{$\begin{array}{l}\text { Pendapatan Orang } \\
\text { Tua }\left(X_{5}\right)\end{array}$} \\
\hline$<2 \mathrm{jt}\left(D_{51}\right)$ & $\beta_{51}$ & 0.491 & 3.206 & 0.073 & tolak $H_{0}$ \\
\hline $2 \mathrm{jt}-5 \mathrm{jt}\left(D_{52}\right)$ & $\beta_{52}$ & -0.333 & 0.427 & 0.513 & terima $H_{0}$ \\
\hline
\end{tabular}

Tabel 4.2 Hasil Estimasi Parameter dan Uji Wald
\begin{tabular}{|l|c|c|c|c|c|}
\hline \multicolumn{1}{|c|}{ Variabel } & Parameter & Dugaan & Wald & $\boldsymbol{p}$-value & Keputusan \\
\hline \multirow{3}{*}{ Konstanta } & $\alpha_{1}$ & 0.982 & 0.846 & 0.358 & \\
\cline { 2 - 7 } & $\alpha_{2}$ & 2.475 & 5.315 & 0.021 & \\
\cline { 2 - 7 } & $\alpha_{3}$ & 5.912 & 27.454 & 0.000 & \\
\hline $\begin{array}{l}\text { Berat Badan Lahir } \\
\left(X_{3}\right)\end{array}$ & $\beta_{3}$ & 0.394 & 2.546 & 0.111 & terima $H_{0}$ \\
\hline $\begin{array}{l}\text { Pengetahuan Orang } \\
\text { Tua }\left(X_{8}\right)\end{array}$ & $\beta_{8}$ & 0.024 & 11.425 & 0.001 & tolak $\boldsymbol{H}_{\mathbf{0}}$ \\
\hline ASI Ekslusif $\left(D_{61}\right)$ & $\beta_{61}$ & -0.734 & 4.659 & 0.031 & tolak $\boldsymbol{H}_{\mathbf{0}}$ \\
\hline Diare $\left(D_{71}\right)$ & $\beta_{71}$ & 0.813 & 8.525 & 0.004 & tolak $\boldsymbol{H}_{\mathbf{0}}$ \\
\hline $\begin{array}{l}\text { Pendapatan Orang } \\
\text { Tua }<2 \text { jt }\left(D_{51}\right)\end{array}$ & $\beta_{51}$ & 0.431 & 3.152 & 0.076 & tolak $\boldsymbol{H}_{\mathbf{0}}$ \\
\hline
\end{tabular}

terhadap status gizi balita yaitu Pengetahuan orang tua, ASI Ekslusif, Diare, dan Pendapatan orangtua $<2$ jt. Hal ini dilihat dari nilai p-value kurang dari $\alpha=10 \%$ atau nilai $\chi_{\text {hitung }}^{2}$ lebih besar dari $\chi_{\text {tabel }}^{2}$. Dari keempat variabel yang signifikan pada uji sebelumnya kemudian dilakukan estimasi parameter dan uji wald yang dapat dilihat pada Tabel 4.3.

Tabel 4.3 Hasil Estimasi Parameter dan Uji Wald

\begin{tabular}{|l|c|c|c|c|c|}
\hline \multicolumn{1}{|c|}{ Variabel } & Parameter & Dugaan & Wald & $\boldsymbol{p}$-value & Keputusan \\
\hline \multirow{3}{*}{ Konstanta } & $\alpha_{1}$ & -0.319 & 0.222 & 0.638 & \\
\cline { 2 - 6 } & $\alpha_{2}$ & 1.163 & 2.940 & 0.086 & \\
\cline { 2 - 6 } & $\alpha_{3}$ & 4.578 & 38.425 & 0.000 & \\
\hline $\begin{array}{l}\text { Pengetahuan Orang } \\
\text { Tua }\left(X_{8}\right)\end{array}$ & $\beta_{8}$ & 0.025 & 11.542 & 0.001 & tolak $\boldsymbol{H}_{\mathbf{0}}$ \\
\hline ASI Ekslusif $\left(D_{61}\right)$ & $\beta_{61}$ & -0.767 & 5.088 & 0.024 & tolak $\boldsymbol{H}_{\mathbf{0}}$ \\
\hline Diare $\left(D_{71}\right)$ & $\beta_{71}$ & 0.785 & 8.012 & 0.005 & tolak $\boldsymbol{H}_{\mathbf{0}}$ \\
\hline $\begin{array}{l}\text { Pendapatan Orang } \\
\text { Tua }<2 \text { jt }\left(D_{51}\right)\end{array}$ & $\beta_{51}$ & 0.395 & 2.699 & 0.100 & tolak $\boldsymbol{H}_{\mathbf{0}}$ \\
\hline
\end{tabular}

Berdasarkan Tabel 4.3 dapat diketahui bahwa variabel yang berpengaruh secara signifikan terhadap status gizi balita adalah variabel-variabel yang memiliki nilai p- 
value kurang dari $\alpha=10 \%$, sehingga diputuskan tolak $H_{0}$. Terdapat empat variabel yang signifikan yaitu pengetahuan orangtua, ASI Ekslusif, Diare, dan Pendapatan orangtua. Setelah mengetahui variabel-variabel yang berpengaruh, selanjutnya akan dibentuk peluang model logit sebagai berikut:

$$
\begin{aligned}
& P\left(Y \leq 1 \mid x_{i}\right)=\frac{\exp \left(-0.319+0.025 x_{8}+0.395 D_{51}-0.767 D_{61}+0.785 D_{71}\right)}{1+\exp \left(-0.319+0.025 x_{8}+0.395 D_{51}-0.767 D_{61}+0.785 D_{71}\right)}, \\
& P\left(Y \leq 2 \mid x_{i}\right)=\frac{\exp \left(1.163+0.025 x_{8}+0.395 D_{51}-0.767 D_{61}+0.785 D_{71}\right)}{1+\exp \left(1.163+0.025 x_{8}+0.395 D_{51}-0.767 D_{61}+0.785 D_{71}\right)}, \\
& P\left(Y \leq 3 \mid x_{i}\right)=\frac{\exp \left(4.578+0.025 x_{8}+0.395 D_{51}-0.767 D_{61}+0.785 D_{71}\right)}{1+\exp \left(4.578+0.025 x_{8}+0.395 D_{51}-0.767 D_{61}+0.785 D_{71}\right)}
\end{aligned}
$$

Untuk mengetahui besarnya pengaruh keempat variabel tersebut terhadap status gizi balita, maka dilakukan perhitungan nilai odds ratio seperti pada Tabel 4.4.

Tabel 4.4 Nilai Odds Ratio

\begin{tabular}{|l|c|c|}
\hline \multicolumn{1}{|c|}{ Variabel } & $\widehat{\boldsymbol{\beta}}$ & Odds Ratio $=\exp (\widehat{\boldsymbol{\beta}})$ \\
\hline Pengetahuan Ibu $\left(X_{8}\right)$ & 0.025 & 1.025 \\
\hline ASI Ekslusif $\left(D_{61}\right)$ & -0.767 & 0.464 \\
\hline Diare $\left(D_{71}\right)$ & 0.785 & 2.192 \\
\hline Dendapatan Orang Tua $<2$ jt $\left(D_{51}\right)$ & 0.395 & 1.484 \\
\hline
\end{tabular}

Berdasarkan nilai odds ratio yang diperoleh, dapat disimpulkan bahwa setiap kenaikan skor pengetahuan ibu satu poin akan mengakibatkan kenaikan odds (resiko) status gizi stunting (sangat pendek dan pendek) sebesar 1.025 kali dibandingkan status gizi normal dan tinggi. Balita yang menerima ASI Ekslusif memiliki resiko status gizi stunting (sangat pendek dan pendek) sebesar 0.464 kali lebih rendah dibandingkan dengan tidak menerima ASI Ekslusif. Balita yang menderita diare memiliki resiko status gizi stunting (sangat pendek dan pendek) 2.192 kali lebih tinggi dibandingkan dengan tidak menderita diare. Balita memiliki orang tua dengan pendapatan $<2$ jt memiliki resiko status gizi stunting (sangat pendek dan pendek) sebesar 1.484 kali lebih tinggi dibandingkan dengan balita dengan penghasilan orangtua $\leq 2 j t$.

Untuk mengetahui kesesuaian model maka dilakukan uji terhadap model. Statistik uji yang digunakan adalah uji Pearson dengan hipotesis sebagai berikut.

$H_{0}$ : Model sesuai, atau tidak ada perbedaan yang nyata antara hasil observasi dengan kemungkinan hasil prediksi model,

$H_{1}$ : Model tidak sesuai, atau ada perbedaan yang nyata antara hasil observasi dengan kemungkinan hasil prediksi model.

Berdasarkan hasil perhitungan diketahui bahwa nilai $\chi_{\text {hitung }}^{2}>\chi_{\text {tabel }}^{2}$ dan $p$-value sebesar $0.000<\alpha=0.10$ maka tolak $H_{0}$. 
16 Ainun Mardiah Siregar dkk.

\section{Kesimpulan}

Berdasarkan hasil analisis dan pembahasan dapat diambil kesimpulan bahwa pada penelitian ini tinggi balita sebagian besar memiliki status tinggi badan normal dimana sebesar $78.01 \%$ atau berkisar 163 balita dengan masing-masing 90 orang perempuan dan 73 orang laki-laki. Pada penelitian ini variabel prediktor yang diduga memiliki pengaruh terhadap terjadinya stunting dengan taraf nyata $10 \%$ adalah pengetahuan ibu, ASI Ekslusif, Diare, dan pendapatan orangtua.

\section{Daftar Pustaka}

[1] Argesti, A. 2002. Categorical Data Analysis. John Wiley and Sons, New York

[2] Hosmer, D. W and S.Lemeshow. 2000. Applied Logistic Regression. Wiley and Sons, New York

[3] Kementrian Kesehatan Republik Indonesia. 2017. Hasil Pemantauan Status Gizi (PSG) 2016. Jakarta

[4] WHO Press. 2010. Nutrition Landscape Information System (NLIS) Country Profile Indicators: Interpretation Guide. Switzerland 